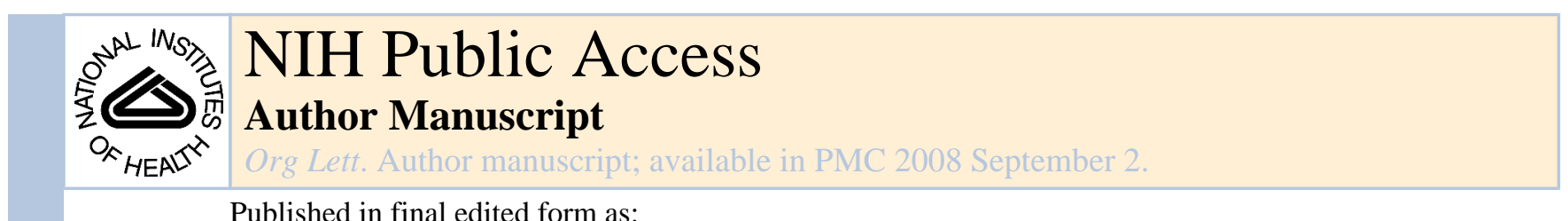

Published in final edited form as:

Org Lett. 2007 May 24; 9(11): 2071-2074. doi:10.1021/ol0704338.

\title{
Biomimetic Synthesis of the Tetracyclic Core of Berkelic Acid
}

\author{
Jingye Zhou and Barry B. Snider \\ Department of Chemistry MS 015, Brandeis University, Waltham, Massachusetts 02454-9110
}

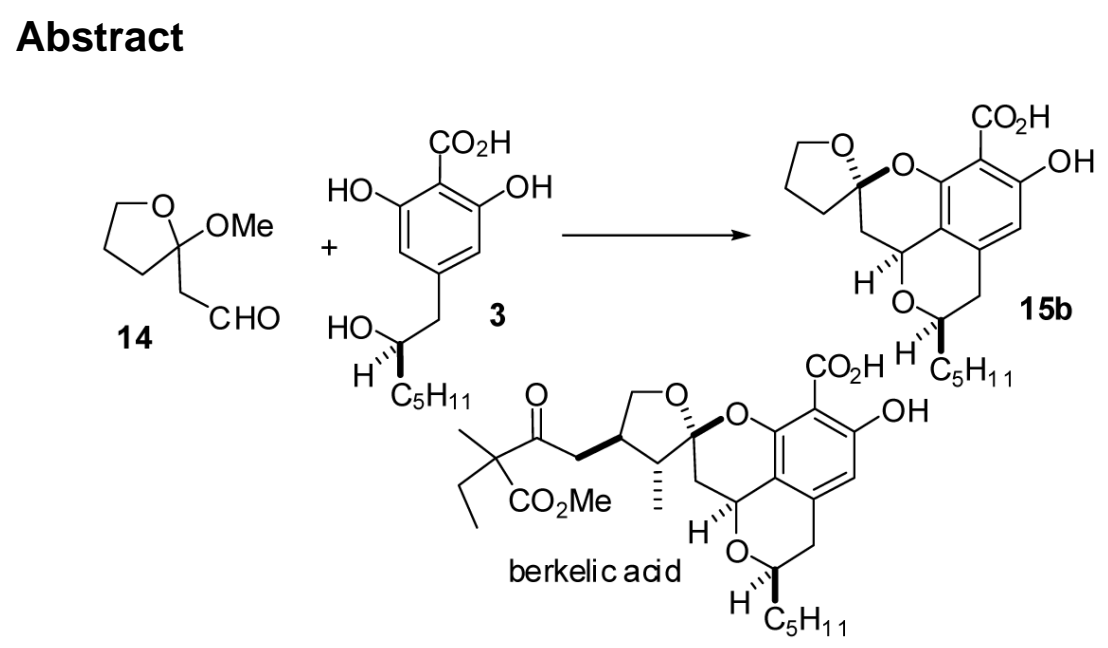

Acid catalyzed condensation of 2,6-dihydroxybenzoic acid 3 with ketal aldehyde 14 in methanol at $25^{\circ} \mathrm{C}$, followed by $\mathrm{CH}_{2} \mathrm{~N}_{2}$ esterification gave a 4:1:4:1 mixture of diastereomers $15 \mathrm{~b}-18 \mathrm{~b}$ in $60 \%$ yield. Equilibration of this mixture with TFA in $\mathrm{CDCl}_{3}$ provided tetracycle $15 \mathrm{~b}$ (83\% yield) with the complete skeleton of berkelic acid. A similar condensation at $0{ }^{\circ} \mathrm{C}$ afforded $15 \mathrm{~b}-18 \mathrm{~b}$ and a reduction product $19 \mathrm{~b}$, which was probably formed by a 1,5-hydride shift.

Stierle and coworkers recently isolated berkelic acid (1), a novel spiroketal with selective anticancer activity, from an acid mine waste fungal extremophile (see Scheme 1). ${ }^{1}$ The structure was assigned based on the analysis of the NMR and mass spectral data. The absolute stereochemistry and the relative stereochemistry of the side chain stereocenter were not assigned. Berkelic acid inhibits MMP-3 and caspase- 1 and shows selective activity toward ovarian cancer OVCAR-3 with a GI 50 of $91 \mathrm{nM}$. We thought that 1 should be accessible by a highly convergent route starting from ketal aldehyde $\mathbf{2}$ and 2,6-dihydroxybenzoic acid $\mathbf{3}$. Acid 3 , a synthetic, and presumably biosynthetic, precursor to pulvilloric acid (4), has been prepared in both racemic ${ }^{2}$ and optically pure forms. ${ }^{3}$

An oxa-Pictet-Spengler cyclization 4 of $\mathbf{2}$ and $\mathbf{3}$ should give isochroman $\mathbf{8}$ (see Scheme 2). These cyclizations are usually suggested to proceed by formation of oxocarbenium ion $\mathbf{6}$, followed by a Friedel-Crafts cyclization to give $\mathbf{8}$. It is also possible that the first step is an intermolecular Friedel-Crafts reaction to give benzylic alcohol 5. Protonation of the alcohol and loss of water will give the stabilized benzylic cation $7^{5}$ that will cyclize to give $\mathbf{8}$. Ketal exchange with loss of methanol will give $\mathbf{9}$ with the complete tetracyclic core of berkelic acid.

snider@brandeis.edu.

Supporting Information Available: Complete experimental procedures, copies of ${ }^{1} \mathrm{H}$ and ${ }^{13} \mathrm{C}$ NMR spectral data, and X-ray crystallographic data (CIF file) for $\mathbf{1 5 b}$. This material is available free of charge via the Internet at http://pubs.acs.org. 
This sequence generates two new stereocenters so that four isomers can be produced. The anomeric center of berkelic acid (1), with the oxygen of the tetrahydrofuran ring axial on the pyran ring, is probably in the more stable configuration. Therefore this center should be readily set by equilibration. Oxa-Pictet-Spengler cyclizations that give 1,3-disubstituted isochromans often give mainly the cis disubstituted products such as $\mathbf{8}$ under kinetically controlled conditions. ${ }^{6}$ In some cases, equilibration via the benzylic cations analogous to $\mathbf{7}$ and $\mathbf{1 0}$ afforded mainly the more stable trans product. ${ }^{7}$ Therefore it might be possible to use either kinetically or thermodynamically controlled conditions to obtain the desired diastereomer.

Model ketal aldehyde 14 was prepared to investigate this sequence (see Scheme 3). Addition of the lithium enolate of tert-butyl acetate to $\gamma$-butyrolactone (11) afforded ester $\mathbf{1 2}$ as a mixture of hydroxy ketone and hemiketal tautomers. ${ }^{8}$ Reaction in acidic methanol converted this mixture to ketal ester $\mathbf{1 3}$ in $56 \%$ overall yield. Reduction of $\mathbf{1 3}$ with DIBAL-H at $-78{ }^{\circ} \mathrm{C}$ provided crude ketal aldehyde $\mathbf{1 4}$, which decomposed on chromatography and was used without purification.

Reaction of acid $3^{9}$ with 2-3 equiv of crude ketal aldehyde 14 in $\mathrm{MeOH}$ containing Dowex $50 \mathrm{WX} 8-400-\mathrm{H}^{+}$for $12 \mathrm{~h}$ at $25^{\circ} \mathrm{C}$ afforded a mixture of the desired tetracyclic acids 15a-18a that was treated with diazomethane in ether to give a 4:1:4:1 mixture of methyl esters

15b-18b, respectively, in $60 \%$ yield. The four isomers were separated and characterized spectroscopically. Molecular mechanics with conformational searching calculated relative strain energies for $\mathbf{1 5 b} \mathbf{b} \mathbf{1 8 b}$ of $28.14,28.56,30.51$, and $30.84 \mathrm{kcal} / \mathrm{mol}$, respectively. ${ }^{10}$ This suggests that isomers $\mathbf{1 5 b}$ and $\mathbf{1 6} \mathbf{b}$ with $\mathrm{H}_{3^{\prime} \mathrm{a}}$ and $\mathrm{H}_{5^{\prime}}$ cis are significantly more stable than isomers $17 \mathrm{~b}$ and $\mathbf{1 8 b}$ with these hydrogens trans. Isomers $15 \mathrm{~b}$ and $\mathbf{1 7 b}$ with the tetrahydrofuran oxygen axial on the pyran ring are slightly more stable than $\mathbf{1 6 b}$ and $\mathbf{1 8 b}$, respectively, as expected from the anomeric effect. The formation of $\mathbf{1 7 b}$ as one of the two major products indicates that incomplete equilibration occurs under these reaction conditions.

The coupling constants to $\mathrm{H}_{3^{\prime} \mathrm{a}}$ are 10-12 and 5-6 Hz indicating that this hydrogen is axial in all four conformers. The coupling constants between the benzylic methylene group and the axial hydrogen $\mathrm{H}_{5}$, in $\mathbf{1 5 b}(J=10.7,4.2 \mathrm{~Hz})$ and $\mathbf{1 6 b}(11.7$ and $3.9 \mathrm{~Hz})$ are close to the values calculated for both $\mathbf{1 5 b}$ and $\mathbf{1 6 b}$ of 11.2 and $4.6 \mathrm{~Hz}$. The coupling constants between the benzylic methylene group and $\mathrm{H}_{5^{\prime}}$ in $\mathbf{1 7} \mathbf{b}(8.8$ and $4.9 \mathrm{~Hz})$ and $\mathbf{1 8 b}(8.8$ and $3.9 \mathrm{~Hz})$ are close to the calculated values of 7.0 and $4.7 \mathrm{~Hz}$ for $\mathbf{1 7 b}$ and 7.2 and $4.5 \mathrm{~Hz}$ for $\mathbf{1 8 b}$, suggesting that these molecules are mixtures of the conformer drawn with a boat ring and the pentyl substituent in a pseudoequatorial conformation and the chair conformer with an axial pentyl substituent.

The spiroketal stereochemistry can be assigned from the chemical shift of the axial proton $\mathrm{H}_{3^{\prime} \mathrm{a}}$, which is in a 1,3- relationship to the anomeric center. The difference between the two diastereomers is especially pronounced in $\mathrm{C}_{6} \mathrm{D}_{6} \cdot{ }^{11}$ In this solvent, $\mathrm{H}_{3^{\prime} \mathrm{a}}$ of $\mathbf{1 5 b}$ and $\mathbf{1 7 b}$ with an axial oxygen absorbs at $\delta 5.00$ and $\delta 5.12$, respectively whereas $\mathrm{H}_{3^{\prime} \mathrm{a}}$ of $\mathbf{1 6} \mathbf{b}$ and $\mathbf{1 8 b}$ with an equatorial oxygen absorbs at $\delta 4.41$ and 4.63 , respectively. Finally, NOEs between $\mathrm{H}_{3^{\prime} \mathrm{a}}$ and $\mathrm{H}_{5^{\prime}}$ in $\mathbf{1 5 b}$, between $\mathrm{H}_{3^{\prime} \mathrm{a}}$ and both $\mathrm{H}_{3}$ and $\mathrm{H}_{5^{\prime}}$ in $\mathbf{1 6} \mathbf{b}$, between $\mathrm{H}_{3^{\prime} \mathrm{a}}$ and both $\mathrm{H}_{6^{\prime}}$ and the side chain $\mathrm{CH}_{2}$ group in $\mathbf{1 7} \mathbf{b}$, and between $\mathrm{H}_{3^{\prime} \mathrm{a}}$ and $\mathrm{H}_{3}, \mathrm{H}_{6^{\prime}}$, and the side chain $\mathrm{CH}_{2}$ group in $\mathbf{1 8 b}$ confirmed the stereochemical assignments.

The molecular mechanics calculations suggest that the desired isomer $\mathbf{1 5 b}$ is most stable. Our structures $\mathbf{1 5 b} \mathbf{b} \mathbf{- 1 8 b}$ differ from simple isochromans in which the trans isomer may be more stable ${ }^{7}$ because of the additional fused ring in $\mathbf{1 5 b} \mathbf{b} \mathbf{1 8 b}$. Therefore equilibration of the mixture of four isomers should significantly increase the percentage of $\mathbf{1 5 b}$ in the mixture. We were delighted to find that equilibration of the above $4: 1: 4: 1$ mixture of $\mathbf{1 5 b}-\mathbf{1 8 b}$ with $0.2 \%$ TFA in $\mathrm{CDCl}_{3}$ for $12 \mathrm{~h}$ provided a 20:2:1:0 mixture of $\mathbf{1 5 b}-\mathbf{1 8 b}$, respectively, from which $\mathbf{1 5 b}$ could be isolated in $50 \%$ overall yield from acid $\mathbf{3}$. The stereochemistry of $\mathbf{1 5 b}$ was confirmed by X- 
ray crystal structure determination. Basic hydrolysis of pure $\mathbf{1 5 b}$ completed the synthesis of berkelic acid model 15a, which was contaminated with 5\% of 16a resulting from spiroketal equilibration during hydrolysis, in $83 \%$ yield (see Scheme 4).

Our initial reactions of $\mathbf{3}$ and $\mathbf{1 4}$, which were carried out at $0{ }^{\circ} \mathrm{C}$ rather than $25^{\circ} \mathrm{C}$, afforded a 4:1:7:1 mixture of $\mathbf{1 5 b}-\mathbf{1 8 b}$, respectively in only $41 \%$ yield. Additionally, we isolated $30 \%$ of $80 \%$ pure reduced product $\mathbf{1 9 b}$ as a mixture of diastereomers. Acetylation of impure $19 \mathrm{~b}$ afforded 20b which could be isolated in pure form in $72 \%$ yield (see Scheme 5).

The formation of $19 \mathrm{~b}$ was unexpected and the presence of the two diastereomers complicated the structure proof. We therefore prepared acid $\mathbf{2 1}{ }^{12}$ by carboxylation of olivetol and treated it with $\mathbf{1 4}$ to generate the reduced product $\mathbf{2 2}$ in $27 \%$ yield (see Scheme 6). ${ }^{13}$

Reduced products 19b and 22 are probably formed by a second equivalent of aldehyde acting as a hydride donor. 1,3-Dioxane $\mathbf{2 3}$ could be formed from a benzylic alcohol analogous to $\mathbf{5}$ and a second equivalent of aldehyde (see Scheme 7). Protonation of $\mathbf{2 3}$ would give benzylic cation 24, which could undergo a 1,5-hydride shift to give 25. Hydrolysis of the aryl ester of 25 and spiroketalization would form 19a. Alternatively, a benzylic alcohol analogous to 5 could react with a second equivalent of aldehyde to give 1,3-dioxane 26. Protonation of $\mathbf{2 6}$ would give benzylic cation $\mathbf{2 7}$ that could undergo a 1,5-hydride shift to give ester $\mathbf{2 8}$. Hydrolysis of the ester of $\mathbf{2 8}$ and spiroketalization would form 19a. Only traces of these reduced products are formed when the reaction is carried out at $25^{\circ} \mathrm{C}$. This is consistent with the proposed mechanism because the highly ordered transition state for a 1,5-hydride shift should have a large negative entropy of activation and therefore be relatively favored at lower temperatures. 1,5-Hydride shifts of this type are uncommon, but some related examples have recently been reported. ${ }^{14}$

The formation of reduced product 19a is inconsistent with the usually proposed mechanism for the oxa-Pictet-Spengler cyclization. If the isochroman ring is formed by an intramolecular Friedel-Crafts reaction of an oxocarbenium ion analogous to $\mathbf{6}$, reduction by a 1,5-hydride shift is unlikely. Such a pathway is impossible for the conversion of $\mathbf{2 1}$ to $\mathbf{2 2}$ since there is no alcohol in the side chain. This suggests that the oxa-Pictet-Spengler cyclization of 3 to give 15-18 proceeds at least partially by a Friedel-Crafts reaction to give a benzylic alcohol analogous to 5 followed by cyclization to form the isochroman ring. 15

In conclusion, acid catalyzed condensation of acid $\mathbf{3}$ with ketal aldehyde $\mathbf{1 4}$ in methanol at 25 ${ }^{\circ} \mathrm{C}$, followed by $\mathrm{CH}_{2} \mathrm{~N}_{2}$ esterification, and equilibration with TFA in $\mathrm{CDCl}_{3}$ affords tetracycle 15b (50\% overall yield) with the complete skeleton of berkelic acid. Application of this route to the total synthesis of berkelic acid (1) using a more highly functionalized ketal aldehyde $\mathbf{2}$, in which $\mathrm{R}$ is a precursor to the side chain, is currently in progress.

\section{Supplementary Material}

Refer to Web version on PubMed Central for supplementary material.

\section{Acknowledgment}

We are grateful to the National Institutes of Health (GM-50151) for support of this work. We thank the National Science Foundation for the partial support of this work through grant CHE-0521047 for the purchase of an X-ray diffractometer. We thank Chun-Hsing Chen, Brandeis University, for determining the crystal structure of $\mathbf{1 5 b}$.

\section{References}

1. Stierle AA, Stierle DB, Kelly K. J. Org. Chem 2006;71:5357-5360. [PubMed: 16808526] 
2. Bullimore BK, McOmie JFW, Turner AB, Galbraith MN, Whalley WB. J. Chem. Soc. C 1967:12891293.

3. Rödel T, Gerlach H. Liebigs Ann. Chem 1997:213-216.

4. For a review see: Larghi EL, Kaufman TS. Synthesis 2006:187-220.

5. Protonated $o$ - and $p$-quinone methides are important resonance contributors stabilizing cation 7 .

6 (a). DeNinno MP, Schoenleber R, Perner RJ, Lijewski L, Asin KE, Britton DR, MacKenzie R, Kebabian JW. J. Med. Chem 1991;34:2561-2569. [PubMed: 1652023] (b) Wünsch B, Zott M. Liebigs Ann. Chem 1992:39-45. (c) Anderson BA, Hansen MM, Harkness AR, Henry CL, Vincenzi JT, Zmijewski MJ. J. Am. Chem. Soc 1995;117:12358-12359. (d) Giles RGF, Rickards RW, Senanayake BS. J. Chem. Soc., Perkin Trans. 1 1998:3949-3956. (e) Bianchi DA, Rúa F, Kaufman TS. Tetrahedron Lett 2004;45:411-415.

7. See reference $6 \mathrm{~d}$ and footnote 15 in reference $6 \mathrm{a}$.

8. Kim P, Olmstead MM, Nantz MH, Kurth MJ. Tetrahedron Lett 2000;41:4029-4032.

9. Prepared as described by Whalley in reference 2, except that 3,5-dimethoxyphenylacetyl chloride was treated with $n-\mathrm{C}_{5} \mathrm{H}_{11} \mathrm{MgCl}$ and $\mathrm{CuI}$ rather than an organocadmium reagent.

10. PCMODEL version 8.0 from Serena Software was used with MMX. Calculations were carried out on analogues with the pentyl side chain replaced by a methyl group to minimize irrelevant conformational complexity.

11 (a). Pothier N, Goldstein S, Deslongchamps P. Helv. Chim. Acta 1992;75:604-620. (b) Doubský J, Šaman D, Zedník J, Vašíčková S, Koutek B. Tetrahedron Lett 2005;46:7923-7926.

12 (a). Asahina Y, Asano J. Ber. Dtsch. Chem. Ges 1932;65B:475-482. (b) Liu, G.; Szczepankiewicz, BG.; Pei, Z.; Xin, Z.; Janowick, DA. U.S. Patent App. 2002-072,516. 2002. Chem. Abstr 2002; $137: 33535$.

13. The free phenol $\mathbf{2 2}$ could not be fully purified by chromatography. Pure $\mathbf{2 2}$ was obtained by conversion to the acetate ester, careful chromatography, and hydrolysis of the acetate with $\mathrm{K}_{2} \mathrm{CO}_{3}$ in $\mathrm{MeOH}$.

14 (a). Yoshimatsu M, Hatae N, Shimizu H, Kataoka T. Chem. Lett 1993:1491-1494. (b) Krohn K, Flörke U, Höfker U, Träubel M. Eur. J. Org. Chem 1999:3495-3499. (c) Pastine SJ, Sames D. Org. Lett 2005;7:5429-5431. [PubMed: 16288523] (d) Tobisu M, Chatani N. Angew. Chem. Int. Ed 2006;45:1683-1684.

15. For another oxa-Pictet-Spengler cyclization that may proceed by both mechanisms see: Zhang X, Li X, Lanter JC, Sui Z. Org. Lett 2005;7:2043-2046. [PubMed: 15876050] 


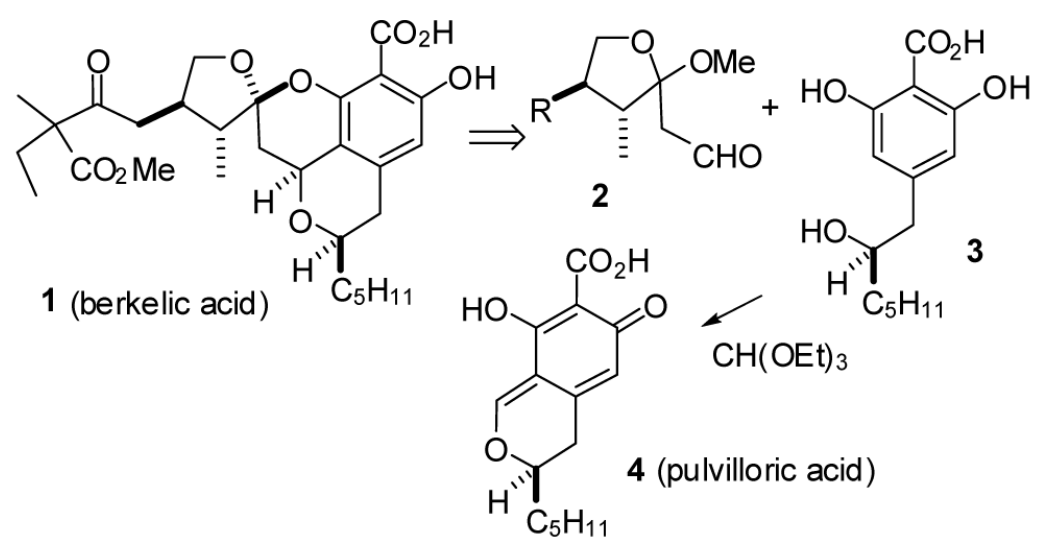

Scheme 1.

Retro- and Biosynthesis of Berkelic Acid (1) 


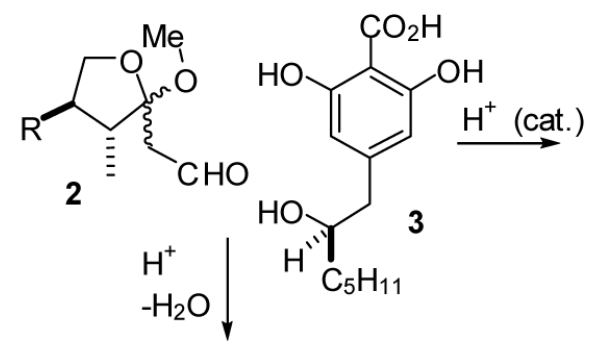

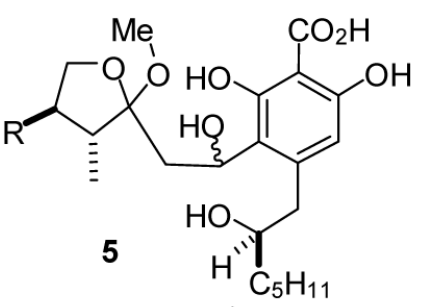<smiles>[R]C1CO[C@@](CC=O)([C@H](C)OC)[C@H]1Cc1cc(O)c(C(=O)O)c(O)c1</smiles>

$\downarrow-\mathrm{H}^{+}$

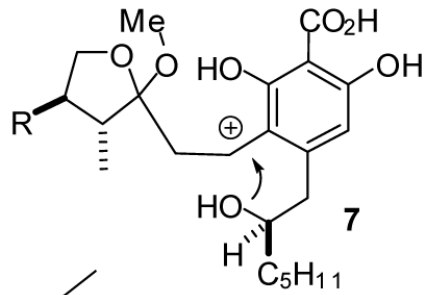<smiles>[3H][IH+]C</smiles><smiles>C[PH2+]</smiles>

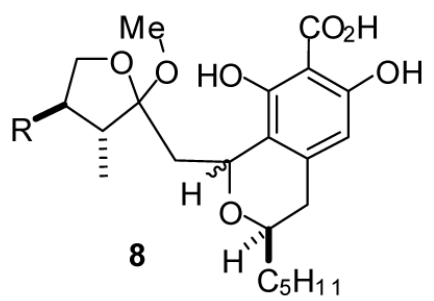<smiles>COC(O)C(=O)O</smiles>

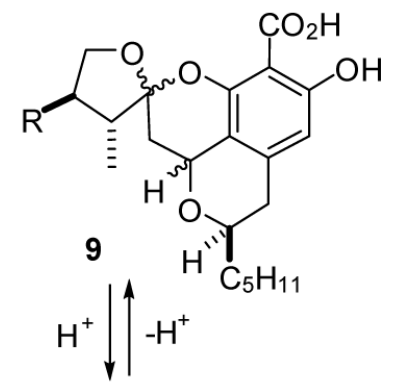

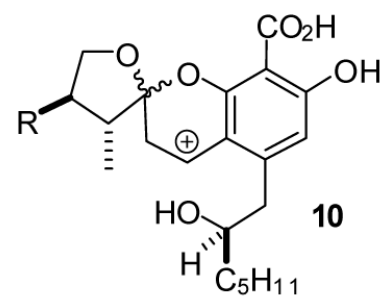

Scheme 2.

Proposed Oxa-Pictet-Spengler Cyclization to Give 9 

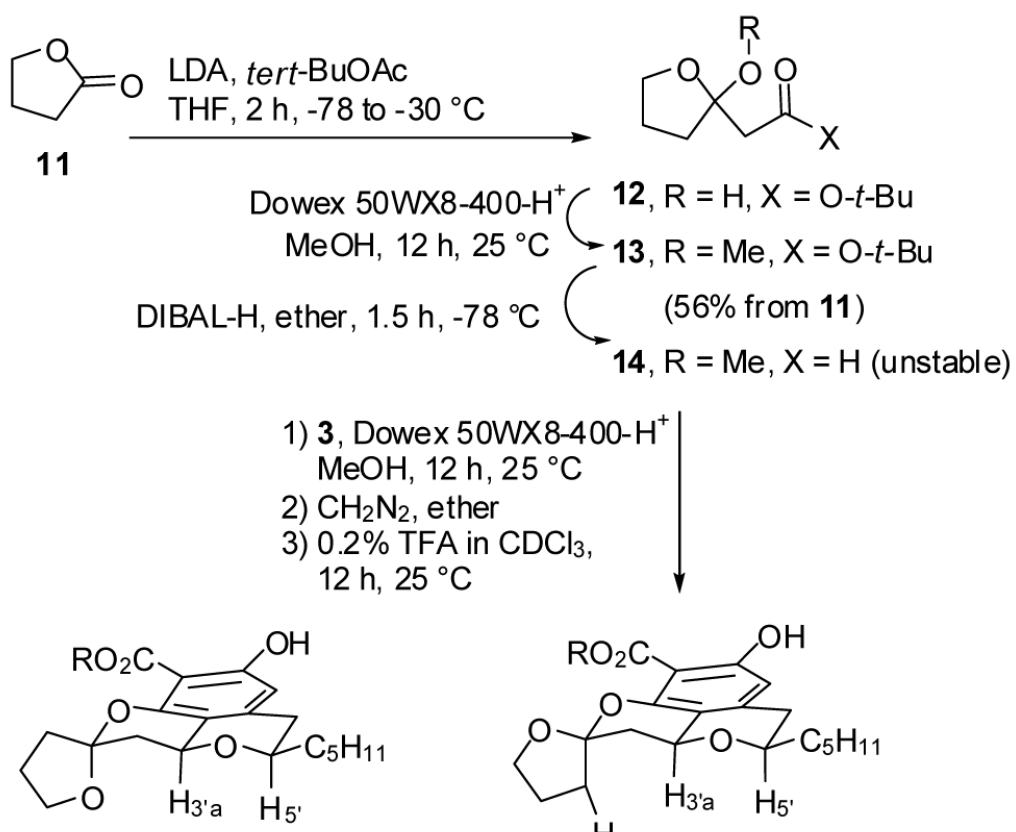
3, Dowex $50 \mathrm{WX} 8-400-\mathrm{H}^{+}$
$\mathrm{MeOH}, 12 \mathrm{~h}, 25^{\circ} \mathrm{C}$
2) $\mathrm{CH}_{2} \mathrm{~N}_{2}$, ether
$0.2 \%$ TFA in $\mathrm{CDCl}_{3}$
$12 \mathrm{~h}, 25^{\circ} \mathrm{C}$

$15 \mathrm{a}, \mathrm{R}=\mathrm{H}$

$15 b, R=M e(24 \%)$ (50\% after TFA equilibration)

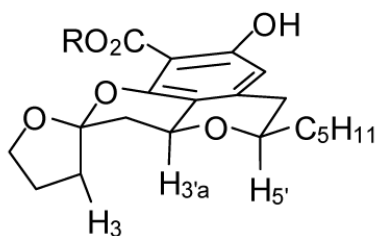

16a, $\mathrm{R}=\mathrm{H}$

$16 b, R=\operatorname{Me}(6 \%)$

( $5 \%$ after TFA equilibration)
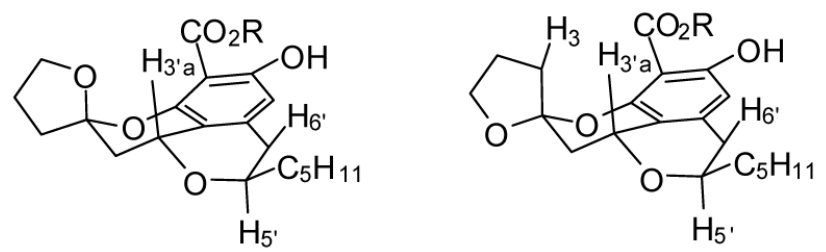

$17 \mathrm{a}, \mathrm{R}=\mathrm{H}$

$17 b, R=M e(24 \%)$ ( $<2 \%$ af ter TFA equilibration)

$18 \mathrm{a}, \mathrm{R}=\mathrm{H}$

18b, $R=\operatorname{Me~}(6 \%)$

( $0 \%$ after TFA equilibration)

Scheme 3

Preparation of Model 15b 


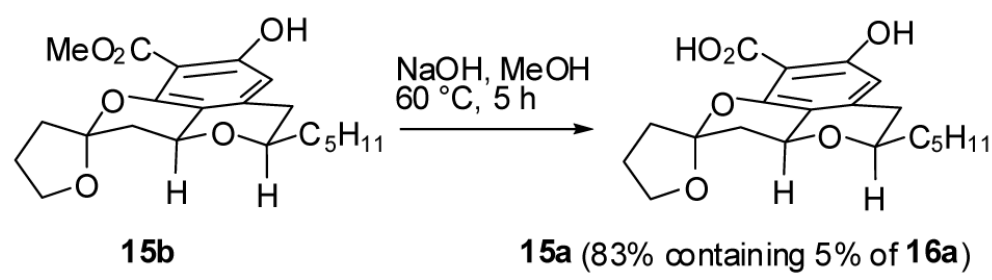

Scheme 4.

Synthesis of Tetracyclic Model 15a 
$15 b-18 b(4: 1: 7: 1,41 \%)$

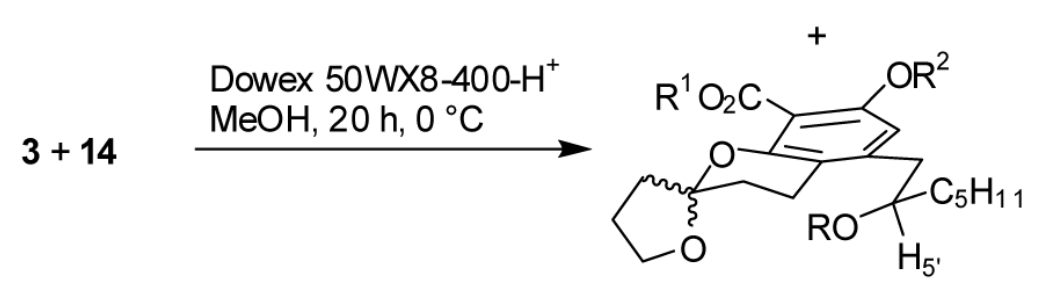

$\mathrm{CH}_{2} \mathrm{~N}_{2}$, ether $\left(19 a, \mathrm{R}^{1}=\mathrm{R}^{2}=\mathrm{H}\right.$

$\mathrm{Ac}_{2} \mathrm{O}$, pyr, $\quad$ 19b, $\mathrm{R}^{1}=\mathrm{Me}, \mathrm{R}^{2}=\mathrm{H}(30 \%, 80 \%$ pure $)$

$12 \mathrm{~h}, 25^{\circ} \mathrm{C}$ 20b, $\mathrm{R}^{1}=\mathrm{Me}, \mathrm{R}^{2}=\mathrm{Ac}(72 \%)$

Scheme 5 . 


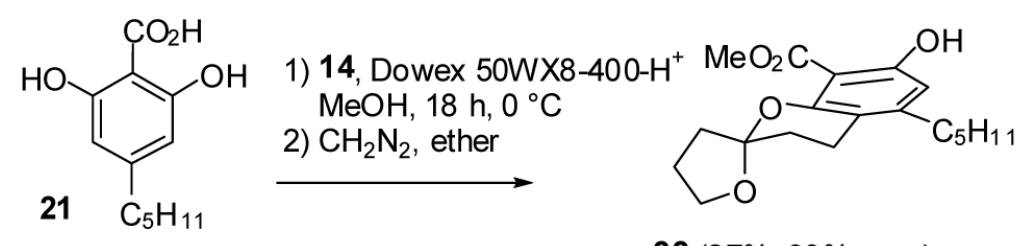

$22(27 \%, 90 \%$ pure $)$

Scheme 6. 


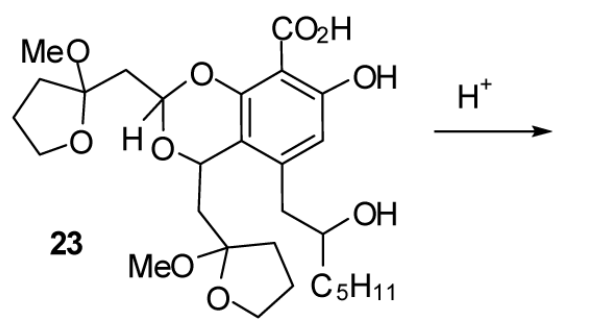

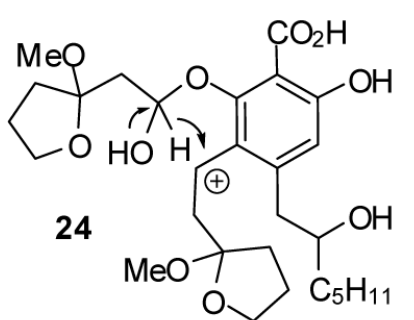

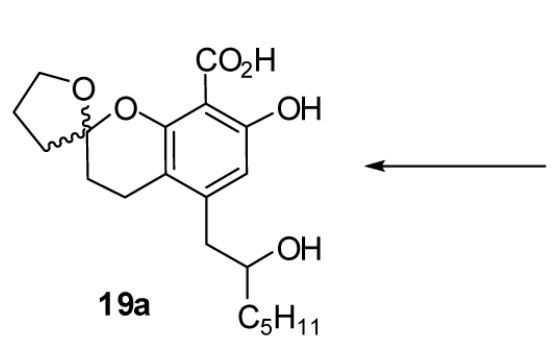<smiles>COC1(CCc2c(OC(=O)CC3(OC)CCCO3)c(CC(O)CS)cc(O)c2C(=O)O)CCCO1</smiles>

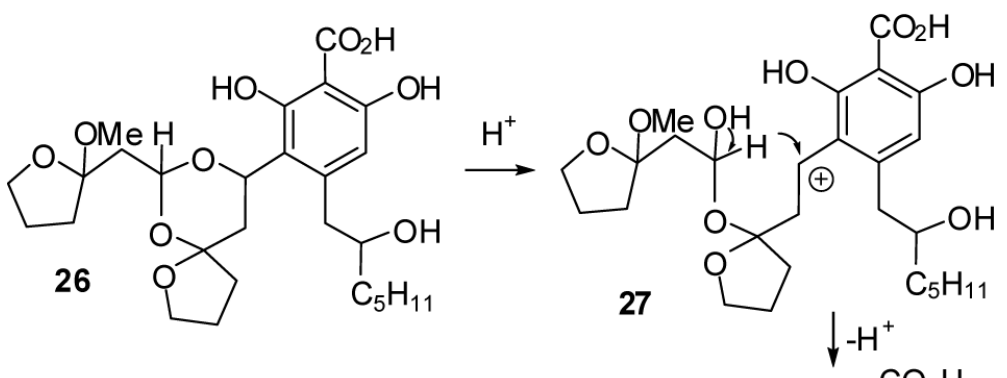

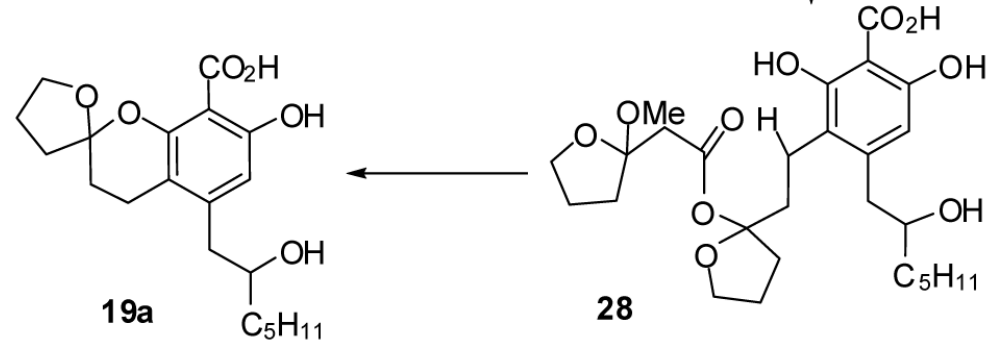

Scheme 7. 